\title{
Letters
}

All letters are subject to editing and may be shortened. General letters can be sent to bjgpdisciarcgp.org.uk (please include your postal address for publication), and letters responding directly to BJGParticles can be submitted online via eLetters. We regret we cannot notify authors regarding publication.

For submission instructions visit: bjgp.org/letters

\section{GP point-of-care ultrasound in the UK}

The editorial by di Martino and colleagues asks whether there is a role for point-of care ultrasound in UK primary care IGP PoC-US), and we agree with the authors that the time is right to explore and develop its use.

Quite apart from the advantages that an early practice-based scan can bring, many scans are requested on patients who are frail, for whom a trip to the local hospital can be a major undertaking. We are also aware of individuals living in residential care who have missed imaging appointments because of the failure of complex transport arrangements.

The skills to carry out a safe ultrasound can be acquired by training, supervision, and practice, and form part of the training of some specialists. GPs, given our vital role in early diagnosis across multiple clinical disciplines, and the varied community settings in which we work, stand to benefit at least as much.

We have set up a GP PoC-US training programme in Somerset, through a collaboration between the Radiology Department at Yeovil District Hospital and the GP practices who were involved in the Symphony Vanguard project Inow collectively known as Symphony Healthcare Services).

We chose four initial scans to learn, for their relative simplicity, and their clinical utility: DVTs, bladder scans (for retention and residual volume), abdominal scans for ascites, and chest ultrasound for pleural effusions. We adopted the Royal College of Radiologists' training guidelines, with logbooks to record scanning experience. A portable ultrasound machine was acquired and configured to be able to upload images to the hospital PACS server. Training has been delivered by a consultant sonographer and his team, with direct teaching, observing scans, scanning under supervision, and training in reporting.

We are now also working with the local palliative care team to develop a community paracentesis service.

We hope, through a process of audit and reflection, to contribute to the evidence that GP PoC-US is effective, safe, and of benefit to our community. One day it could be the 'new normal'.

Christopher G Krasucki,

GP, Somerset, and Research Lead,

Symphony Healthcare Services.

Email: Christopher.KrasuckidYYH.NHS.UK

Steve Savage,

Consultant Sonographer, Yeovil District Hospital.

\section{REFERENCE}

1. di Martino E, Aakjaer Andersen C, Mengel$J ø r g e n s e n ~ T$, et al. Is there a place for pointof-care ultrasound in UK primary care? $\mathrm{Br} \mathrm{J}$ Gen Pract 2020: DOI. https://doi.org/10.3399/ bjgp20X710801.

DOI: https://doi.org/10.3399/bjgp21X714677

\section{MRCGP Recorded Consultation Assessment - the hidden fourth construct}

The MRCGP Recorded Consultation Assessment (RCA) uses recorded consultations, ostensibly to assess three skills: inter-professional; data gathering, technical and assessment; and decision making and clinical management. These are entirely reasonable constructs for an assessment of readiness for safe independent practice.

However, the RCA has a hidden fourth construct: candidates must select cases that align with the examiners' view of reasonable level of 'challenge'. The latest Examiners' Reports highlight that case selection continues to be a major issue, and some candidates have probably failed for this reason.

This alludes to a problem of construct validity: is the skill of identifying 'suitable RCA cases' really a prerequisite for safe, independent general practice? If not, can we justify continuing an assessment that has this hidden fourth construct as a prerequisite skill? Indeed, can 'level of challenge' of a GP consultation even be judged reliably? Even the latest candidate guidance appears somewhat vague in its definition. Furthermore, some candidates are likely to have greater difficulty collecting cases to choose from, with part-time trainees, those in smaller practices, and those in areas with large non-Englishspeaking populations likely to be at a particular disadvantage.

We are now past the early stages of COVID-19 and the ongoing use of the RCA is surely problematic, especially for highstakes 'fail' decisions. Perhaps the RCA should instead be used as a screening test with unsuccessful RCA candidates then sitting the Clinical Skills Assessment (CSA). Smaller numbers of CSA candidates would ensure adequate social distancing. This approach would benefit potentially good candidates with fewer opportunities to record cases or who simply struggle to choose cases that align with the examiners' particular view of 'challenge'.

Chris Williams,

GP and Trainer, Rosebery Medical Centre, Loughborough; Senior GP Educator, Tutor Development and Quality, University of Leicester, Leicester.

Email: cdw4aleicester.ac.uk

DOI: https://doi.org/10.3399/bjgp21X714689

\section{Extracting smoking data from GP electronic health records}

Although health promotion data such as body mass index have been extracted from GP records for many years, there has been far less interest in tabulating numerical smoking data. Focus seems to be on stopping smoking (which is excellent in itself) rather than using smoking information to predict disease at either an individual or population level. This is probably due to the lack of recommended software recording standards for smoking in the computer systems available. This is a 
glaring elephant in the room for the future screening of lung cancer or other smokingrelated diseases.

Nigel J Masters,

Retired GP and GP Administrator, Highfield Surgery, Hazlemere, High Wycombe.

Email: mastersnigeldamail.com

\section{Competing interests}

The author with his practice nurse created the smoking pack year calculator to simplify pack year recording (https://www. smokingpackyears.com).

\section{Relative frequencies of ophthalmia neonatorum and congenital nasolacrimal duct obstruction}

I appreciate the useful article from Maqsood and Mahmood on the identification and diagnosis of herpes simplex ophthalmia neonatorum. 'As McKechnie and Snelson suggest in their response, a key differential for 'sticky eye' in the neonate is congenital nasolacrimal duct obstruction. ${ }^{2}$

A large cohort study of all children in Olmsted County, Minnesota, found that the prevalence of congenital nasolacrimal duct obstruction was $11.3 \%$. Of these cases, over $90 \%$ were identified in primary care. ${ }^{3}$

Ophthalmia neonatorum however is comparatively rare. A survey sent to members of the American Association for Paediatric Ophthalmology and Strabismus found that most ophthalmologists encountered fewer than five cases per year. Of these cases, the most common causative organism was Chlamydia trachomatis. ${ }^{4}$

The diagnostic challenge for the GP is clear. While they will see numerous cases of congenital nasolacrimal duct obstruction, they will rarely encounter ophthalmia neonatorum. From the literature it appears that herpes simplex ophthalmia neonatorum is relatively uncommon even for specialists working in a more selected population.

Given this difficulty, the pragmatic approach of referral of all cases suspicious for infection, as suggested by McKechnie and Snelson, is prudent. Prompt secondary care assessment would then allow timely and effective treatment to prevent sightthreatening complications.

Thomas Weatherby,

Foundation Doctor, North West Anglia

NHS Foundation Trust.

Email: tw418वcam.ac.uk

\section{REFERENCES}

1. Maqsood N, Mahmood U. Herpes simplex ophthalmia neonatorum: a sight-threatening diagnosis. Br J Gen Pract 2020; DOI: https://doi. org/10.3399/bjgp20X712973.

2. McKechnie DGJ, Snelson E. Ophthalmia neonatorum and the role of primary care. [Letter]. Br J Gen Pract 2020; DOI: https://doi.org/10.3399/ bjgp20X713621.

3. Sathiamoorthi S, Frank RD, Mohney BG. Incidence and clinical characteristics of congenital nasolacrimal duct obstruction. $\mathrm{Br} J$ Ophthalmol 2019; 103(4): 527-529.

4. Zloto O, Gharaibeh A, Mezer E, et al. Ophthalmia neonatorum treatment and prophylaxis: IPOSC global study. Graefes Arch Clin Exp Ophthalmol 2016; 254(3): 577-582.

DOI: https://doi.org/10.3399/bjgp21X714905

\section{Gear change: supporting and encouraging cycling on prescription}

I read with great interest the paper written by Heather Jones, which presents the need of 'cycling on prescription' to begin within the walls of the NHS in order to influence and benefit the wider population. ${ }^{1}$

As a fourth-year medical student in London, I am continuously travelling to different hospitals and GP practices across the city, mainly by bicycle. Through my own experience, I must agree with Heather Jones that the provision of cycle amenities at many of these NHS sites is poor. This poor infrastructure, such as limited (if any) access to safe bicycle storage and onsite showers, frequently deters me from cycling to these locations. Evidence shows that lack of safe parking is a major barrier to both cyclists and non-cyclists; conversely, noncyclists state they will feel more enabled to begin cycling if further allocation of bike racks were placed at health centres. ${ }^{2}$
Poor local cycling conditions may make clinicians wary to prescribe cycling. However, the 'focused effort to promote cycling "1 to NHS staff may fail to empower the wider population simply because it does not remedy the largest deterrent to cycling, which is fear of injury to oneself. ${ }^{2}$ One of the main themes of the UK Government's Gear Change policy is to enable and protect people when they cycle. ${ }^{3}$ Proposed Gear Change infrastructure interventions include the development of segregated cycle lanes, which have been proven to reduce the likelihood of cyclist injuries, while simultaneously producing a 'safety in numbers' phenomena. ${ }^{4}$ The Gear Change policy thus has the framework to remedy this large deterrent to cycling, thus hopefully increasing the adherence rate in those who are socially prescribed cycling.

While it can be argued that promoting NHS staff to cycle will increase local cycling conditions, Gear Change aims to improve cycling infrastructure and promote cycling to the UK population as a whole. Through further offers of patient cycle training to mediate patient risk, peer support groups, and loaning of cycles, cycling on prescription may be ushered in as a staple in social prescribing.

Timothy E Yeo,

Fourth-Year Medical Student, Barts and the London School of Medicine and Dentistry.

Email: t.yeolasmd16.qmul.ac.uk

\section{REFERENCES}

1. Jones H. 'Cycling on prescription': a gear change or a wrong turn? Br J Gen Pract 2020; DOI: https:// doi.org/10.3399/bjgp20X713237.

2. Iwińska K, Blicharska M, Pierotti L, et al. Cycling in Warsaw, Poland - perceived enablers and barriers according to cyclists and non-cyclists. Transp Res Part A Policy Pract 2018; 113: 291 301

3. Department for Transport. Gear Change: a bold vision for cycling and walking. 2020. https://assets. publishing.service.gov.uk/government/uploads/ system/uploads/attachment_data/file/904146/ gear-change-a-bold-vision-for-cycling-andwalking.pdf (accessed 14 Jan 2021).

4. Bhatia D, Richmond SA, Loo CKJ, et al. Examining the impact of cycle lanes on cyclist-motor vehicle collisions in the city of Toronto. J Transp Heal 2016; 3(4): 523-528.

DOI: https://doi.org/10.3399/bjgp21X714917 